\title{
Laboratory and field responses of algal nitrate reductase to diel periodicity in irradiance, nitrate exhaustion, and the presence of ammonium
}

\author{
John A. Berges ${ }^{1, *}$, William P. Cochlan ${ }^{2}$, Paul J. Harrison ${ }^{1}$ \\ ' Department of Oceanography, University of British Columbia, Vancouver, British Columbia, Canada V6T 1 Z4 \\ ${ }^{2}$ Hancock Institute for Marine Studies, University of Southern California, Los Angeles, California 90089-0371, USA
}

\begin{abstract}
Use of nitrate reductase (NR) activity as an index of rates of nitrate incorporation in marine phytoplankton has been complicated by inadequate assays, and the high degree of regulation of the enzyme under different non-steady-state conditions. The relationship between NR activity and rates of nitrate incorporation was examined using a modified NR assay (which included bovine serum albumin) under diel periodicity in irradiance, following exhaustion of nitrate, and in the presence of ammonium. Laboratory experiments using the diatom Thalassiosira pseudonana showed that on a $14: 10 \mathrm{~h}$ light: dark cycle, NR activity had 2 distinct peaks within 1 cycle, one in the middle of the light period, and the other towards the end of the dark period. Each of these peaks has been noted in previous work, both in culture and in natural populations, but this is the first description of both in 1 cycle. Throughout the diel cycle, NR activity closely matched rates of nitrate incorporation calculated from increases in particulate nitrogen in the cultures. As nitrate was exhausted in the cultures, NR activity declined in step with nitrate incorporation rates (estimated from nitrate depletion, increases in particulate nitrogen, or the product of cell growth rate and cell nitrogen content). In cultures where nitrate was substituted by ammonium, no NR activity was detected, but when ammonium was exhausted, background contamination of the medium with nitrate (approximately $1 \mu \mathrm{M}$ ) was sufficient to cause the appearance of NR activity and the uptake of nitrate. Daily additions of $2 \mu \mathrm{M}$ ammonium to cultures growing on nitrate had no effect on the relationship between NR activity and nitrate incorporation rate. The NR assay was used in a preliminary study of natural assemblages of phytoplankton in Monterey Bay, California, USA, during a post-upwelling diatom bloom. Diel periodicity in NR activity was observed that was virtually identical to that found in laboratory cultures. Ammonium inhibition on a time scale similar to that seen in culture was also recorded. These preliminary results are promising for the use of NR activity to estimate rates of nitrate incorporation in field population of phytoplankton
\end{abstract}

KEY WORDS: Nitrate reductase - Enzyme activity - Nitrate incorporation - Marine phytoplankton . Thalassiosira pseudonana Diel periodicity · Nutnent exhaustion - Ammonium inhibition

\section{INTRODUCTION}

Activity of the enzyme nitrate reductase (NR) has been proposed as an index of nitrate incorporation (sensu Wheeler 1983, i.e. the combination of inorganic nitrogen into macromolecules) in marine phytoplankton (Eppley et al. 1969, Blasco et al. 1984). Such an

\footnotetext{
- Present address: Oceanic and Atmospheric Sciences Division, Brookhaven National Laboratory, Upton, New York 11973 , USA;E-mail: berges@bnlux1.bnl.gov
}

index would avoid the problems associated with techniques such as ${ }^{15} \mathrm{~N}$ incorporation, which require samples to be contained for incubation periods (see Leftley et al. 1983, Collos et al. 1993). However, many studies have found poor relationships between NR activity and different measurements of nitrate uptake, assimilation and incorporation (Packard et al. 1971, Collos \& Slawyk 1977, Dortch et al. 1979). The reasons for such discrepancies may include inadequate NR assay methods, the lack of a true relationship between NR activity and nitrate incorporation, or the complexity of interactions 
between NR and environmental variables that result in an uninterpretable activity measurement. In recent work, we have demonstrated that if NR assays are properly optimized, a quantitative relationship exists between NR activity and nitrate incorporation rates (functionally defined as nitrogen capable of being retained on glass fiber filters and detected by $\mathrm{CHN}$ analysis). This is true under steady-state light or nutrient limitation, for several species of phytoplankton, including the diatom Thalassiosira pseudonana (Berges \& Harrison 1995a, b)

In the ocean, however, growth and nitrate incorporation are not likely to be in steady state because of factors such as diel periodicity in irradiance, periodic exhaustion of nutrients, and the presence of alternative nitrogen sources, such as ammonium (see Eppley 1981). Under such conditions, NR activity may still provide a good index of nitrate incorporation because these same factors are involved in the regulation of NR activity

Diel periodicity in irradiance affects division cycles, photosynthesis, and cell composition (Chisholm 1981, Prezelin 1992), and also nutrient uptake in microalgae and in natural assemblages of phytoplankton see Syrett 1981, Cochlan et al. 1991, Glibert \& Garside 1992). Diel periodicity has also been demonstrated in NR abundance and activity in higher plants (see Lillo 1983, Campbell 1988, Deng et al. 1991), in microalgae in culture (e.g Eppley et al. 1971, Packard et al. 1971 Smith et al. 1992, Ramalho et al. 1995), and in natural assemblages of phytoplankton (e.g Packard \& Blasco 1974, Collos \& Slawyk 1976, Martinez et al. 1987). However, there are relatively few comparisons between NR activity and nitrate incorporation done over a diel cycle.

In nature, phytoplankton assemblages usually reach plateaus in biomass caused by depletion of a nutrient, often nitrate. Under these conditions, it is unclear how NR activity responds. In cultures, rapid declines in NR activity have been shown to occur in step with decreases in nitrate assimilation (e.g. Morris \& Syrett 1965, Hersey \& Swift 1976), but other work has demonstrated gradual decreases in NR that occur more slowly than decreases in nitrate assimilation (e.g. Syrett \& Peplinska 1988). There are even reports of transient increases in NR activity when nitrogen is depleted, or when algal cells grown on ammonium are transferred to N-free media (e.g. Kessler \& Osterheld 1970, Slawyk \& Rodier 1986, Watt et al. 1992).

In natural environments, nitrate is not the only source of nitrogen available to phytoplankton; ammonium and organic nitrogen are generally present and are used (Antia et al. 1991). Since ammonium is more reduced than nitrate and thus requires less energy for assimilation, it has been argued that ammonium should be a preferred nitrogen source (Syrett 1981). In fact, ammonium has been shown to inhibit the uptake of nitrate in some studies (e.g Syrett 1981) but not in all cases (see Dortch 1990). There is strong evidence that ammonium suppresses NR activity in higher plants (Solomonson \& Barber 1990) and algae (Serra et al. 1978, Dortch et al. 1979, Flynn et al. 1993), but there are also exceptions (Harrison 1976, Collos \& Slawyk 1980). If NR is to be used as an index of nitrate incorporation, it must be determined whether the inhibition by ammonium of nitrate uptake and the inhibition of NR activity are coordinated.

In the present study, NR activity and nitrogen incorporation rates were compared in cultures of Thalassiosira pseudonana that had been: (1) grown on light: dark cycles, (2) starved of nitrogen, or (3) grown on (or in the presence of ) ammonium. The goal of these experiments was to determine whether these conditions affected the applicability of NR activity as an index of nitrate incorporation.

Finally, if NR activity is related to nitrate incorporation in unialgal cultures, there remains the issue of whether the relationship is applicable to natural phytoplankton assemblages. The issue is made complex because nitrate incorporation is a relatively difficult measurement to make in many field situations. As a first step we chose to apply the NR assay to natural assemblages and to compare patterns of diel periodicity and ammonium inhibition with those found in cultures. We sought an environment with a phytoplankton community dominated by diatoms, and having high biomass and growth rates for greater analytical sensitivity, and high nitrate but low ambient ammonium concentrations. Coastal upwelling zones, and the California (USA) current upwelling system in particular, met these criteria very well.

\section{MATERIALS AND METHODS}

General culture conditions and measurements. Cultures of Thalassiosira pseudonana (Hustedt) Hasle \& Heimdal $(3 \mathrm{H}$ clone, NEPCC 58) were obtained from the North East Pacific Culture Collection (Dept. Oceanography, Univ. British Columbia) and maintained on artificial medium (ESAW, based on Harrison et al. 1980 ) at $17.5^{\circ} \mathrm{C}$, as previously described (Berges \& Harrison 1993). Semicontinuous batch cultures were maintained in logarithmic growth phase by dilution with fresh medium, except as noted below, and were stirred and bubbled with air as previously described. Specific growth rates $(\mu)$ were measured by in vivo fluorescence, or cell counts. Cell abundance and volumes were determined using a TAII Coulter Counter with a $70 \mu \mathrm{m}$ aperture and a population accessory. Cell 
carbon and nitrogen were measured by collecting samples onto precombusted $13 \mathrm{~mm}$ Gelman A/E filters, and using a Carlo Erba CNS analyzer, with sulfanilamide as a standard.

Samples for NR activity were collected on $25 \mathrm{~mm}$ Whatman GF/F filters and measured using an improvement of Eppley's assay (1978) (Berges \& Harrison 1995a). Samples were always analyzed immediately after collection. NR was extracted in $200 \mathrm{mM}$ phosphate buffer, pH 7.9 containing 5 mM EDTA, $0.1 \%$ (v/v) Triton X-100, $0.03 \%$ (w/v) dithiothreitol, $0.3 \%$ $(\mathrm{w} / \mathrm{v})$ polyvinyl pyrrolidone, and $3 \%(\mathrm{w} / \mathrm{v})$ bovine serum albumin (BSA). Assays were conducted at the growth temperature in $200 \mathrm{mM}$ phosphate buffer, pH 7.9 containing $0.2 \mathrm{mM}$ NADH. Reactions were initiated by the addition of $10 \mathrm{mM} \mathrm{KNO}_{3}$ and monitored spectrophotometrically, following the oxidation of $\mathrm{NADH}$ at $340 \mathrm{~nm}$ in a temperature-controlled LKB Ultrospec II spectrophotometer, interfaced to a personal computer (Berges \& Virtanen 1993). Absorbance changes over time were converted to unit (U) of enzyme activity, where $1 \mathrm{U}$ is the amount of enzyme needed to catalyze the conversion of $1 \mu \mathrm{mol}$ of substrate to product per minute, using a millimolar extinction coefficient of 6.22 . This method was verified against the rate of nitrite production as previously described (Berges \& Harrison 1995a).

Light: dark cycle experiments. Cultures were grown in $6 \mathrm{l}$ glass flat-bottomed boiling flasks at $16^{\circ} \mathrm{C}$ in an environmental chamber. Irradiance on a 14:10 h light:dark cycle was provided by fluorescent lights (Vitalites), attenuated with neutral density screening. Irradiance was measured using a QSL 100 light meter (Biospherical Instruments, San Diego, CA). Four cultures were grown through a minimum of 8 generations, 2 at $45 \mu \mathrm{mol}$ quanta $\mathrm{m}^{-2} \mathrm{~s}^{-1}, 2$ at $6 \mu \mathrm{mol}$ quanta $\mathrm{m}^{-2} \mathrm{~s}^{-1}$. Initial culture medium nitrate concentration in these experiments was $225 \mu \mathrm{M}$. Cultures in logarithmic growth phase were sampled every 3 h over a $24 \mathrm{~h}$ cycle. At each sampling, $25 \mathrm{ml}$ samples were filtered (25 mm GF/F) and frozen for nutrient analyses. Dissolved nitrate, nitrite, ammonium, silicate, and phosphate were analyzed within 1 mo with a Technicon AutoAnalyzer II® using methodology described by Freiderich \& Whitledge (1972). Samples were also taken and analyzed for fluorescence, cell numbers and volumes, carbon, nitrogen, and NR activity. Nitrate incorporation rates were calculated from the change in particulate nitrogen in the cultures over each $3 \mathrm{~h}$ sampling interval, and compared with NR activities.

Nitrate depletion experiment. Three 11 cultures of Thalassiosira pseudonana were grown under continuous irradiance at $115 \mu \mathrm{mol}$ quanta $\mathrm{m}^{-2} \mathrm{~s}^{-1}$. Culture medium was as described previously, but nitrate concentration was $110 \mu \mathrm{M}$. Cells were maintained in loga- rithmic growth phase for 8 generations prior to Day 0 , and allowed to grow into stationary phase. $\mathrm{pH}$ was monitored to ensure that $\mathrm{CO}_{2}$ did not become limiting. Beginning on Day 3, for $5 \mathrm{~d}$, samples were taken daily for nutrients, cell numbers and volume, carbon and nitrogen. On Days 3, 4, and 6, NR activity was measured. For Day 3, near the end of logarithmic growth, nitrate incorporation rate was calculated from the product of cell nitrogen content and specific growth rate $(\mu)$; for Days 4 to 7 it was estimated from the rate of depletion of nitrate from the medium, or the rate of increase in particulate nitrogen in the culture. Changes in cell composition over time were evaluated by performing linear regression analyses of composition versus time and comparing the slopes of these regressions with zero, using $t$-tests (Wilkinson 1990).

Effects of ammonium and ammonium pulsing. Six 11 cultures of Thalassiosira pseudonana were grown under continuous irradiance at $115 \mu \mathrm{mol}$ quanta $\mathrm{m}^{-2}$ $\mathrm{s}^{-1}$. Cultures were grown as described previously, except that the nitrogen source was either $75 \mu \mathrm{M}$ nitrate for 2 cultures $\left(\mathrm{NO}_{3}\right.$ treatment), or $75 \mu \mathrm{M}$ ammonium (added as ammonium chloride) for 2 cultures $\left(\mathrm{NH}_{4}\right.$ treatment). Two additional cultures were grown on nitrate-enriched medium $(75 \mu \mathrm{M})$, but each day a pulse of ammonium sufficient to bring the ambient concentration to $2 \mu \mathrm{M}$ was added ( $\mathrm{P}$ treatment). This treatment was chosen because a level of 1 to $2 \mu \mathrm{M}$ ammonium is generally thought to affect nitrate uptake and NR activity (see Syrett 1981, Dortch 1990). Cells were maintained in logarithmic growth phase for 8 generations, and then sampled for cell numbers, cell volumes, carbon, and nitrogen. NR activity was determined at each sampling. Nutrients were sampled at $16 \mathrm{~h}$ before the experiment and immediately before NR samples were taken. From the changes in nitrate or ammonium concentrations, rates of nutrient uptake were calculated and expressed as specific daily rates (i.e. $\mathrm{d}^{-1}$, as for growth rate). Nitrogen incorporation rates were calculated from the change in particulate nitrogen in the cultures over each $3 \mathrm{~h}$ sampling interval. For composition, growth rate and $\mathrm{NR}$ data, $\mathrm{NO}_{3}$, $\mathrm{NH}_{4}$ and $\mathrm{P}$ treatments were compared using 1-way ANOVA designs, followed by Tukey multiple comparison tests, with $\alpha$ set at 0.95 (Wilkinson 1990).

Field measurements. Field data were collected aboard the RV 'Point Sur' during May 1993 (Cruise SU93-2) at $\operatorname{Stn} 41\left(36^{\circ} 47.77^{\prime} \mathrm{N}, 121^{\circ} 54.75^{\prime} \mathrm{W}\right)$. Niskin water bottles (10 l) equipped with silicone rubber springs and fittings were used to sample water from the $50 \%$ light penetration depth $(3 \mathrm{~m})$. Subsamples were placed into 4 acid-cleaned 20 l polyethylene containers (LMG Reliance), 2 of which received no additions (controls), while the other 2 received additions of ammonium chloride to bring ambient concentrations 
up to $5 \mu \mathrm{M}$. Initial samples $(t=0 \mathrm{~h})$ were taken directly from the Niskin sample bottles. Containers were placed in a seawater-cooled deck incubator and irradiance was adjusted to $50 \%$ of surface irradiance using neutral density screening. Samples for species determination were taken before and after the experiment, preserved in $2 \%$ formalin, and qualitatively examined to determine the dominant taxa. Sampling was repeated at approximately $4 \mathrm{~h}$ intervals for $32 \mathrm{~h}$. At each time, samples for nutrient analyses (nitrate and ammonium), particulate nitrogen, and chl a were taken. Ammonium samples were analyzed manually within $24 \mathrm{~h}$ using the method of Parsons et al. (1984) and measuring absorbance in a $10 \mathrm{~cm}$ cuvette in a Hewlett Packard model 8452A spectrophotometer. Samples for nitrate were frozen for later analysis using a Technicon AutoAnalyzer II (see Freiderich \& Whitledge 1972). Single $460 \mathrm{ml}$ samples were taken from each container and NR assays performed within $1 \mathrm{~h}$. Homogenization of samples and NR assays were performed as above, but activity was monitored using timed, stopped assays for nitrite production (Eppley 1978), and incubating samples at the in situ temperature $\left(10\right.$ to $\left.12^{\circ} \mathrm{C}\right)$ in deck incubators with flowing seawater $A$ refrigerated centrifuge was not available, and thus homogenates were used directly. Reactions were stopped with $550 \mu \mathrm{M}$ zinc acetate, then samples were centrifuged, and homogenate volumes corrected for the volume of filter fibres, which averaged $0.2 \mathrm{ml}$ for a filtered sample homogenized in $1 \mathrm{ml}$ of extraction buffer. Subsamples $(0.5 \mathrm{ml})$ of the supernatant were removed, and $20 \mu \mathrm{l}$ of $125 \mu \mathrm{M}$ phenazine methosulphate (PMS) was added to oxidize the remaining NADH (Scholl et al. 1974) before assaying for nitrite. NR activity was scaled to particulate nitrogen. Particulate nitrogen was collected on $25 \mathrm{~mm}$ precombusted GF/F filters, and frozen for later analyses using a Europa Scientific RoboPrep Tracermass mass spectrometer. Simultaneous nitrate and ammonium uptake measurements were made using the stable isotope ${ }^{15} \mathrm{~N}$. In this study we report only on the patterns of diel periodicity and ammonium inhibition; the relationship between NR activity and incorporation rates will be the subject of a future paper (Cochlan \& Berges unpubl.).

\section{RESULTS}

\section{Light: dark cycle experiments}

Prior to the experimental period, growth rates based on increases in cell numbers were: $0.90( \pm 0.02$, standard error of the meanj $\mathrm{d}^{-1}$ for high-light-grown cultures, and $0.13( \pm 0.02) \mathrm{d}^{-1}$ for low-light-grown cultures (Fig. 1A). Over the $24 \mathrm{~h}$ experimental period, it was

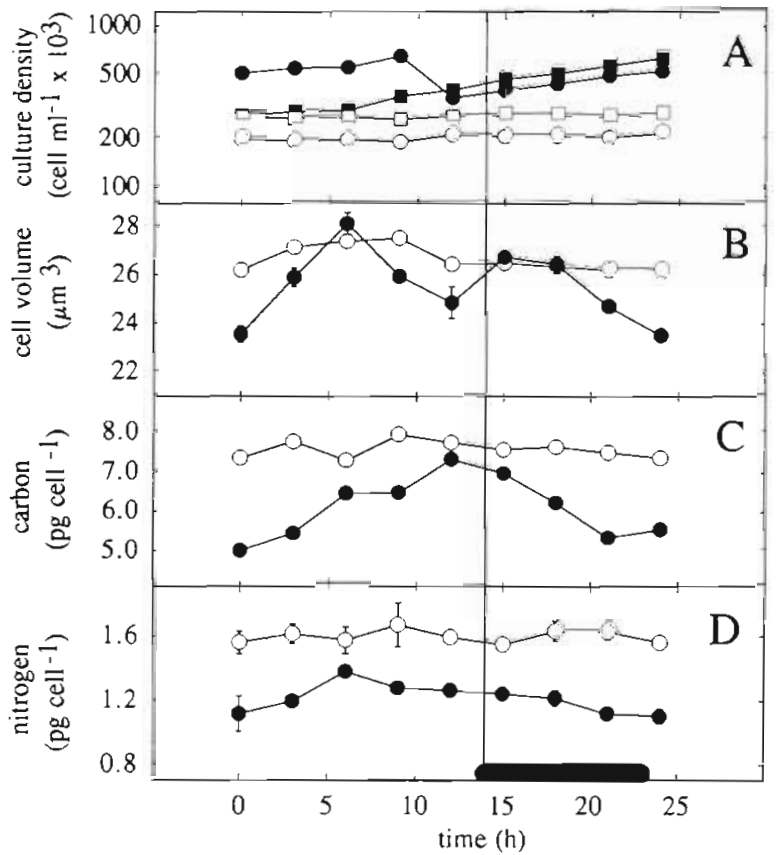

Fig. 1 Thalassiosira pseudonana. Growth characteristics of log phase cultures grown on $14: 10$ h light:dark cycles. (A) Culture densities; (B) cell volume; (C) carbon; and (D) nitrogen. Cultures were grown at high light $\left(45 \mu \mathrm{mol}\right.$ quanta $\mathrm{m}^{-2}$ $\left.\mathrm{s}^{-1} ; \bullet, \mathbf{0}\right)$, or low light $\left(6 \mu \mathrm{mol}\right.$ quanta $\left.\mathrm{m}^{-2} \mathrm{~s}^{-1} ; 0,0\right)$. Points in (A) represent single determinations; points in (B), (C) and (D) represent the mean of duplicate determinations from 2 separate cultures. Error bars represent $\pm 1 \mathrm{SE}$ of mean values Solid bar indicates the dark period. Note that 1 high-light culture (@) was diluted with fresh medium at approximately $10 \mathrm{~h}$, and that the $y$-axis of (A) is logarithmic

intended that culture density remain $<6 \times 10^{5}$ cells $\mathrm{ml}^{-1}$ so that cultures would remain in logarithmic growth phase. For one of the high-light grown cultures, cell density approached this limit, so at $10 \mathrm{~h}$, the culture was diluted approximately by half. Despite this disturbance, growth rates and compositional trends in this culture were not different from those of its replicate. No pattern in cell division was found; cell numbers increased evenly in light and in darkness at similar rates.

In terms of cell composition, there was little variation in low-light-grown cultures for any parameter measured (Fig. 1). For high-light-grown cultures, however, distinct diel patterns were seen in cell volume and cell carbon content (Fig. 1B, C). Cell volume showed peaks in the middle of the light period, and at the beginning of the dark period (Fig. 1B). Cell carbon increased during the light period and decreased in the dark (Fig. 1C). Nitrogen followed neither of these patterns (Fig. 1D).

In terms of NR activity per cell, there was a diel periodicity in both low-and high-light cultures (Fig. 2) 

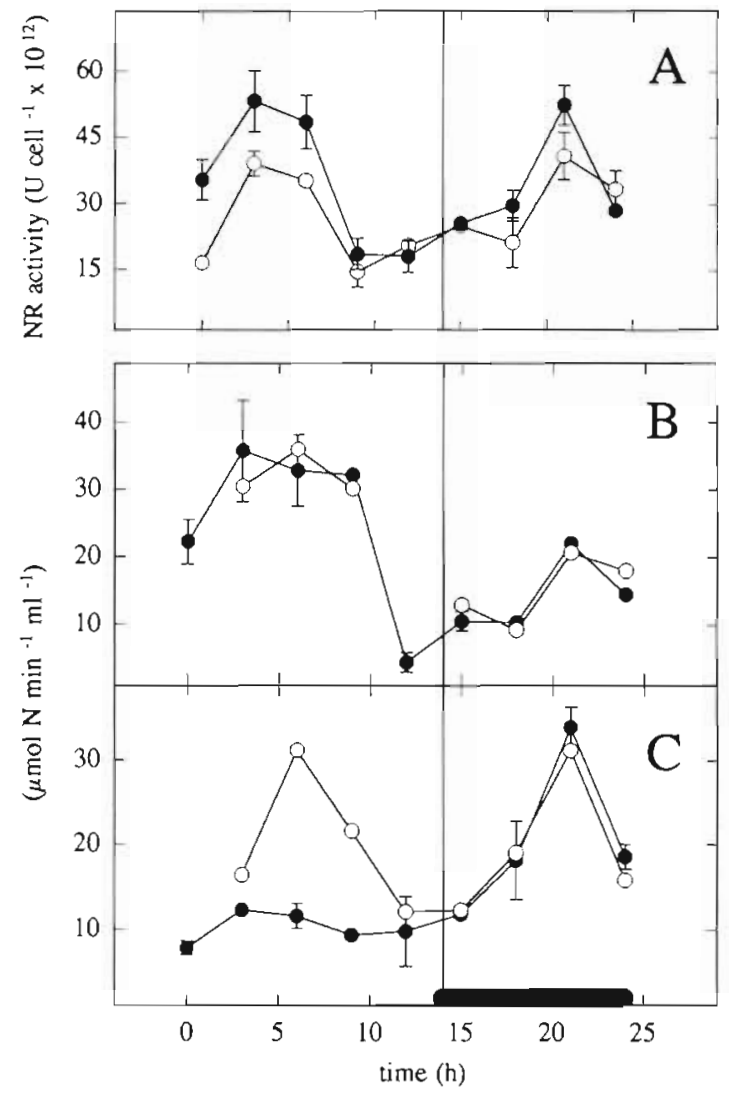

Fig. 2. Thalassiosira pseudonana. Nitrate reductase activity in log phase cultures grown on 14:10 h light: dark cycles. (A) NR activity cell ${ }^{-1}$ at low $(O)$ or high $(\bullet)$ irradiance. (B, C) NR activity $(\bullet)$ or calculated nitrate incorporation rate $(O)$ in 2 cultures grown at high irradiance. For NR activity, each point represents the mean of 2 separate cultures, and error bars repre-

sent \pm 1 SE of mean. Solid bar indicates the dark period

There were 2 peaks in activity, 1 at the middle of the light period, and a second towards the end of the dark period. In high-light cultures, NR activities per $\mathrm{ml}$ of culture matched rates of particulate nitrogen increase throughout the diel cycle extremely closely in one culture (Fig. 2B). In the other culture, the match was good, except in the first 3 sampling periods when particulate nitrogen increases exceeded NR activity (Fig. 2C). Nitrate, phosphate and silicate were never depleted, and only low levels $(<0.5 \mu \mathrm{M})$ of nitrite or ammonium were recorded. As is evident in Fig. 1A, low-light cultures grew almost an order of magnitude more slowly than those in high light. Under these conditions, where growth and nitrate uptake was very low, the coefficient of variation in particulate nitrogen measurements was as high as $50 \%$, and was therefore inadequate for estimating nitrate incorporation. If NR activity and particulate nitrogen for each low-light culture in each sampling period were used to estimate the particulate nitrogen concentration at the next sampling period, these predictions were always within the ranges of increases observed, given the high variability (data not shown). This suggests that NR activities in low-light cultures were within the observed range of nitrate incorporation rates

\section{Nitrate depletion experiment}

Cultures growth rates started to decline from exponential between Days 2 and 3, although cell numbers continued to increase until Day 5 (Fig, 3A). pH over the

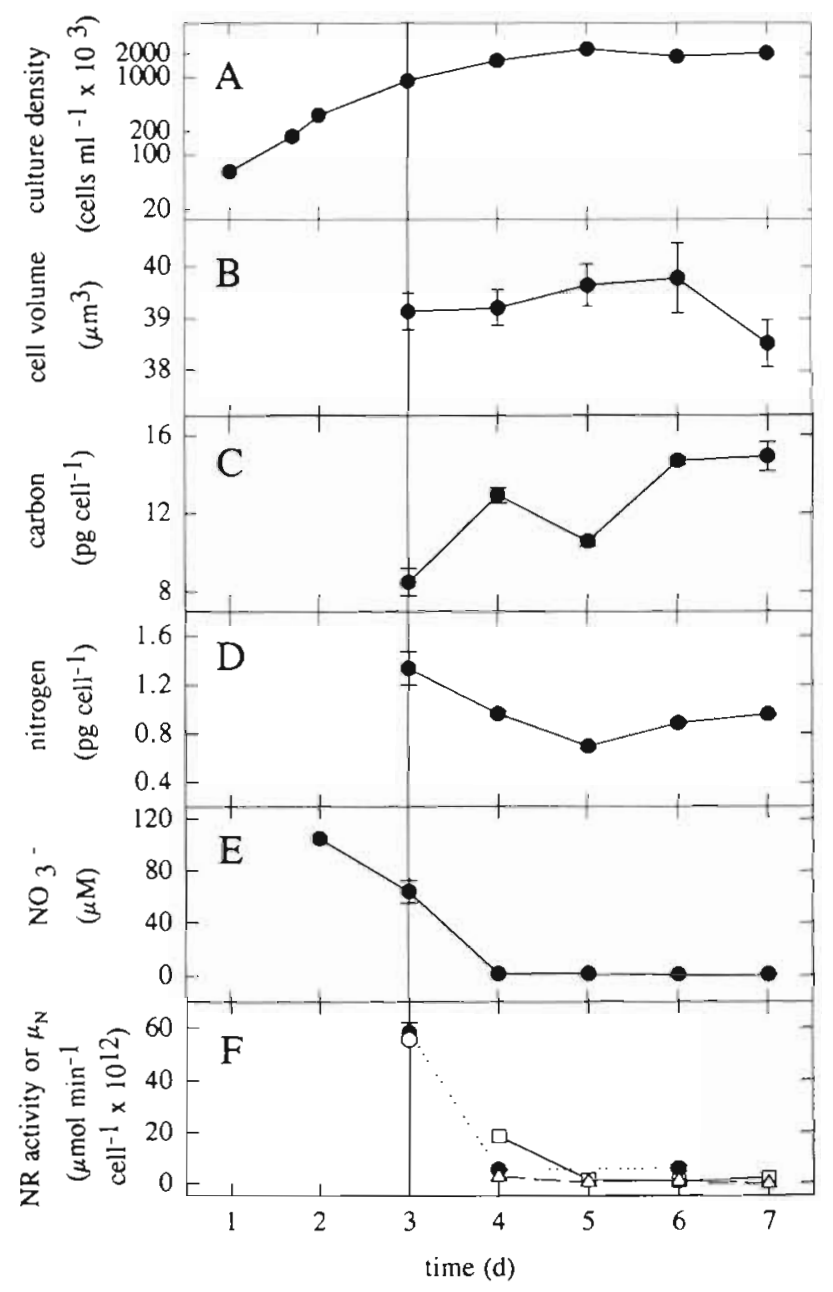

Fig. 3. Thalassiosira pseudonana. Patterns of growth, cell composition and nitrogen metabolism in cultures moving from logarithmic growth (indicated by the vertical line) to stationary phase. (A) Culture density; (B) cell volume; (C) carbon; (D) nitrogen; (E) ambient nitrate concentrations; and (F) NR activity $(\bullet)$, or rate of nitrate incorporation $\left(\mu_{N}\right)$ calculated from growth rate and nitrogen quota $(O)$, increase in particulate nitrogen ( $\square$ ), or depletion of nitrate from the medium $(\Delta)$. Except for calculated rates, each point represents the mean of determinations from 3 replicate cultures. Error bars represent $\pm 1 \mathrm{SE}$, or if not seen, are less than the size of the symbol. Note that not all measurements were made at each sampling time 
experimental period remained relatively constant at 8.2 to 8.5 indicating that significant $\mathrm{CO}_{2}$ depletion did not occur. Nitrate was the first nutrient exhausted between Days 4 and 5 (Fig. 3E); silicate was detectable until Day 6 and phosphate always greater that $5 \mu \mathrm{M}$. Low levels of nitrite and ammonium (ca $1 \mu \mathrm{M}$ ) were seen up to Day 5, but were not detectable by the end of the experiment.

Cell volume did not change over the experiment (Fig. 3B; $\mathrm{p}>0.05$ ), while cell carbon content increased (Fig. 3C; $p<0.001$ ), and nitrogen content decreased (Fig. 3D; $p<0.05$ )

NR activity fell over the course of the experiment (Fig. 3F). NR activity generally followed rates of nitrate incorporation calculated from nitrate depletion or increase in particulate nitrogen, but NR was still detectable on Day 6 , at which point nitrate had been decreased below detection and there were no further increases in particulate nitrogen in the cuitures.

\section{Effects of ammonium and ammonium pulsing}

In cultures grown on ammonium, cells were significantly greater in volume and carbon than either those

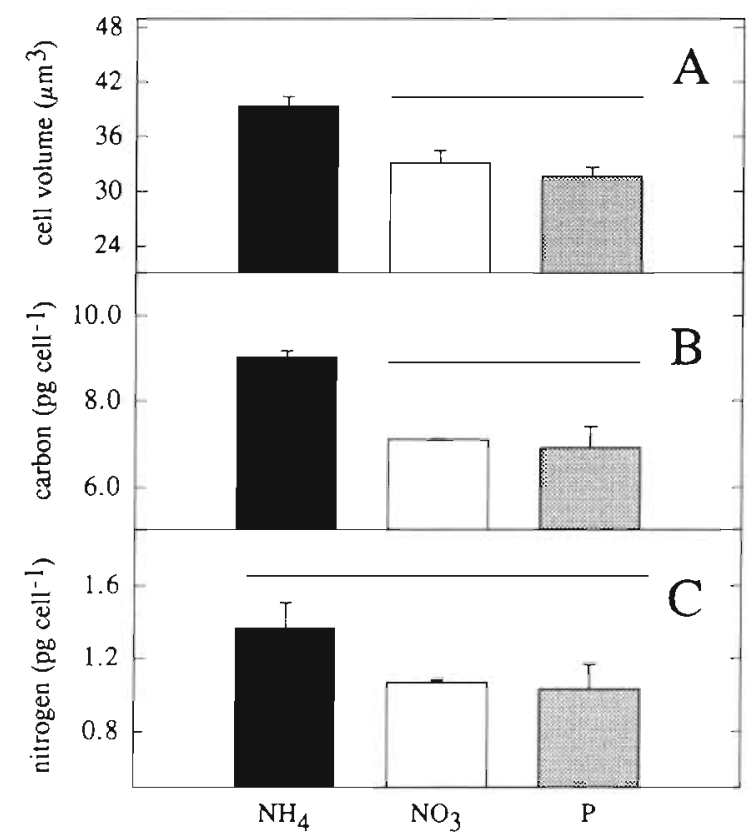

Fig. 4. Thalassiosira pseudonana. Cell composition in log phase cultures grown with $75 \mu \mathrm{M}$ ammonium $\left(\mathrm{NH}_{4}\right.$, solid bars), $75 \mu \mathrm{M}$ nitrate $\left(\mathrm{NO}_{3}\right.$, open bars), or $75 \mu \mathrm{M}$ nitrate with daily pulses of $2 \mu \mathrm{M}$ ammonium ( $P$, hatched bars). (A) Cell volume; (B) carbon; (C) nitrogen. Each bar represents the mean of 2 separate cultures. Error bars represent $\pm 1 \mathrm{SE}$ of means. Treatments not significantly different trom one another at $p=0.05$ are joined by lines over the bars grown on nitrate or pulsed with ammonium (Fig. 4A, $B)$. No significant differences in nitrogen were found amongst the treatments (Fig. 4C)

Ammonium-grown cultures grew significantly faster than nitrate-grown or ammonium-pulsed cultures (Fig. 5A). In terms of nutrient use and NR activities, the 2 ammonium-grown cultures behaved differently, and so they are presented separately (Fig. 5). Ammonium was depleted below detection limits in one culture $\left(\mathrm{NH}_{4}-1\right)$, but remained above $6 \mu \mathrm{M}$ in the other $\left(\mathrm{NH}_{4}\right.$ 2). Nitrate levels in the ammonium-grown cultures were on the order of $1 \mu \mathrm{M}$, due to background contamination of the $\mathrm{NaCl}$ salt used in the artificial medium. Nitrate-grown cultures used only nitrate, and did so at rates consistent with their growth rates (Fig. 5B). Both ammonium-grown cultures used ammonium, but a significant use. of nitrate was seen in the culture in which ammonium was exhausted $\left(\mathrm{NH}_{4}-2\right)$. NR activity and nitrogen incorporation rates (calculated from the product of growth rate and cell nitrogen content) were not different for nitrate-grown and ammonium-pulsed cul-

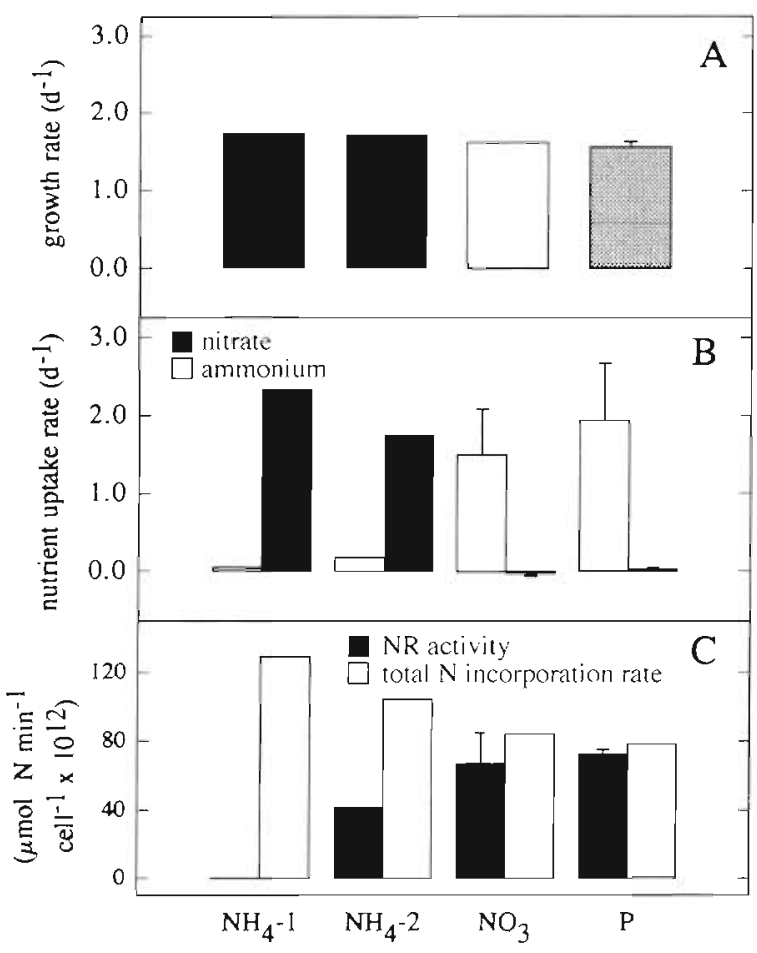

Fig. 5. Thalassiosira pseudonana. Effects of $75 \mu \mathrm{M}$ ammonium $\left(\mathrm{NH}_{4}-1, \mathrm{NH}_{4}-2\right), 75 \mu \mathrm{M}$ nitrate $\left(\mathrm{NO}_{3}\right)$, or $75 \mu \mathrm{M}$ nitrate with daily pulses of $2 \mu \mathrm{M}$ ammonium $(\mathrm{P})$ on growth of cultures. (A) Specific growth rate (based on cell numbers); (B) specific nutrient uptake rates for nitrate and ammonium; (C) NR activity and calculated nitrogen (nitrate + ammonium) incorporation rate. Each bar represents the mean and $\pm 1 \mathrm{SE}$ of 2 cultures, except ammonum cultures which are shown separately since their responses differed between replicates (see 'Results') 
tures (Fig. 5C; $\mathrm{p}>0.5$ in both cases). In the ammonium-grown culture, where ammonium was not exhausted, no NR activity was detected, however, in the other ammonium culture, $\mathrm{NH}_{4}$ had significant $\mathrm{NR}$ activity (Fig. 5C)

\section{Field measurements}

Microscopic examination showed that the species in the Monterey Bay, California, study were predominantly diatoms, with approximately $80 \%$ of cells being (in order of abundance) Thalassiosira spp., Chaetoceros spp., Pseudonitzschia spp., and Skeletonema costatum.

Rates of increase of $\mathrm{chl} a$ and particulate $\mathrm{N}$ were very similar in control and ammoniumenriched containers over the $36 \mathrm{~h}$ of the experiment. Community growth rates $(\mu)$ were estimated at $0.79 \mathrm{~d}^{-1}$ (control) and $0.74 \mathrm{~d}^{-1}$ (ammonium-enriched), based on increases in chl a or particulate $N$. Over the same time period, nitrate concentrations decreased in both sets of containers, but nitrate decreased more rapidly in control containers to $7 \mu \mathrm{M}$, versus $11 \mu \mathrm{M}$ in ammonium-spiked containers (Fig. 6A, C). Ammonium increased slightly over time in control containers, from undetectable levels to $0.45 \mu \mathrm{M}$ by 36 h (Fig. 6A). Ammonium declined steadily in containers with ammonium added until $28 \mathrm{~h}$ when concentrations were no different from control containers (Fig. 6C).

NR activity showed a diel periodicity in both control and ammonium-spiked containers, but because ammonium also had an effect on NR activity, the trend was clearest in control containers (Fig. 6B, D). Activity was low at the beginning of the light period, rose to a peak and then declined by the beginning of the dark period. Towards the end of the dark period, NR activity increased, but fell once again by the first sampling of the next light period. This pattern closely matched that found for Thalassiosira pseudonana cultures (Fig. 2A; see dotted line in Fig. 6B). NR activity in ammoniumspiked containers was identical to that in control containers until $12 \mathrm{~h}$ sampling time (Fig. 6D). Thereafter, NR activity was significantly lower in ammoniumspiked versus control containers, declining to undetectable levels by $20 \mathrm{~h}$ (Fig. 6D). This corresponded to the time when ammonium concentrations fell below $2 \mu \mathrm{M}$ (Fig. 6C). After this, NR activity in ammoniumspiked containers increased, and was not significantly different from activity in control containers in the last sampling

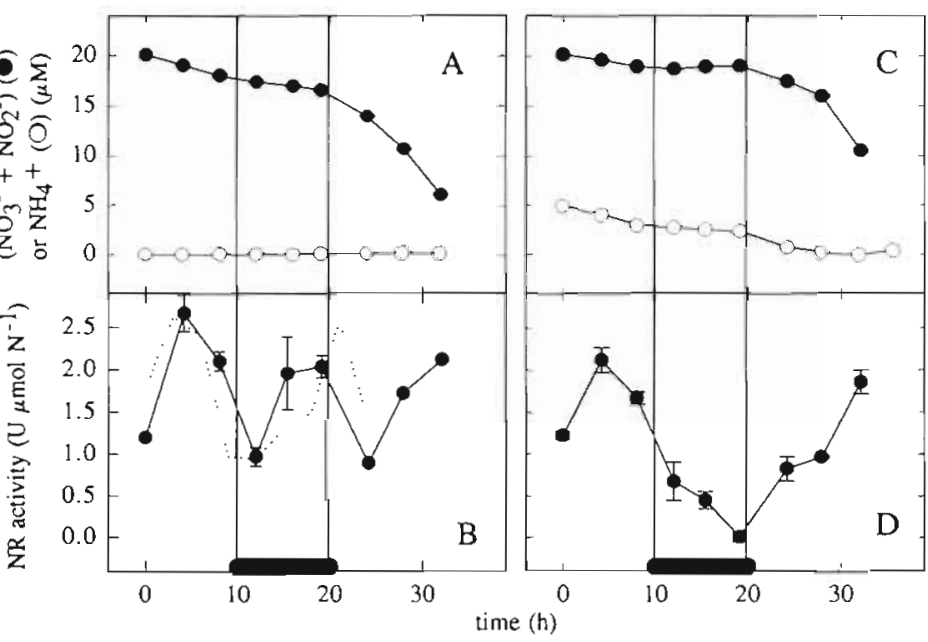

Fig. 6. Changes in ambient concentrations of nitrate (•) and ammonium (0), and in NR activity over time for contained natural populations of hytoplankton from Monterey Bay, California. Cultures received either A, B) no nitrogen additions or (C, D) $5 \mu \mathrm{M}$ ammonium, added at $t=0 \mathrm{~h}$. Each point represents the mean of 2 separate cultures. Error bars repreent $\pm 1 \mathrm{SE}$, or if absent are smaller than the symbols. Cultures were grown under $50 \%$ natural irradiance. Solid bar indicates the dark perod. Dotted curve in (B): the pattern in NR activity observed in laboratory cultures of Thalassiosira pseudonana (see Fig. 2A), with the $y$-axis adjusted to a similar scale

\section{DISCUSSION}

\section{Effects of diel periodicity in irradiance}

There was no detectable diel periodicity in cell division of Thalassiosira pseudonana under the conditions used in the present study. Nelson \& Brand (1979) studied cell division patterns in 7 clones of T. pseudonand, and found that periodicity of division was species and clone specific. In at least 4 clones of $T$. pseudonana division rates were nearly constant throughout the light: dark cycle.

Patterns of cell volume over diel cycles have been investigated previously. As Chisholm (1981) reports, patterns in diatoms are often complex. For Thalassiosira weissflogii, there was a bimodal pattern with maximal volumes occurring at midmorning and just prior to the light-dark transitions. This was correlated with cell division cycles. A similar bimodal pattern with different timing was seen here, but there were no associated division cycles. There are few data for other cell composition parameters.

In culture, and in control containers in the field, NR activity showed a double peak in the diel cycle, which did not simply correlate with changes in cell size or composition. Results from lab and field are similar. The comparison was facilitated because the light:dark cycle was $14 \mathrm{~h}$ light: $10 \mathrm{~h}$ dark in both cases, but the precise timing of the pattern differed. This is probably 
due to differences in the light regime; culture chamber lights are simply switched off and on, while in natural settings irradiance is a continuously varying function of the time of day. A pattern with midday and predawn peaks in activity has not previously been noted, although it can also be discerned in data from cultures of Isochrysis galbana (Flynn et al. 1993). Three patterns have been commonly documented. The first, where activity shows a peak in the light period and very low levels at night, has been demonstrated in higher plants (Deng et al. 1991), macroalgae (Gao et al. 1992) and microalgae (Packard et al. 1971, Collos \& Slawyk 1976, Smith et al. 1992, Ramalho et al. 1995). Martinez et al. (1987) found a variation on this pattern in natural populations of marine phytoplankton; NR activity showed a double peak in the middle of the light period. The second pattern is a monotonic increase in the light and a decrease in the dark, as have been reported in barley leaves (Lillo 1983). Finally, increases in activity just before dawn and declines during the day have been found in chemostat cultures of Emiliania huxleyi (Eppley et al. 1971), and in natural marine phytoplankton assemblages (Packard \& Blasco 1974). There may be at least 2 reasons for these differences. Lillo (1983) found that the particular assay used (e.g. in situ vs in vitro) could give very different patterns and there is great diversity among assays used. Secondly, the sampling frequency of many studies may be insufficient to identify both the peaks. For example, Eppley et al. (1971) sampled irregularly every 5 to $6 \mathrm{~h}$, and Smith et al. (1992) sampled every 4 to $8 \mathrm{~h}$. Thus in some studies one of the peaks in activity may be missed. The reasons for such a pattern remain unclear. Our results are consistent with a synthesis of NR just before dawn; while there may also be a light activation of $\mathrm{NR}$, the process operates on a much shorter time scale than was observed in the present study (Huber et al. 1992). The other midday peak in NR activity may be correlated with peak photosynthesis, because of the tight coupling between carbon fixation and nitrogen incorporation (see Foyer et al. 1994).

In cultures grown on a diel cycle, NR generally correlated very well with calculated rates of increase of particulate nitrogen. Apparently, NR activity was exceeded by calculated rates in one culture (Fig. 2C); the reasons for this are unknown. The correlation between NR and calculated rates agrees with published data, but previously only 12 to $25 \%$ of nitrate incorporation could be accounted for in NR activity (see Eppley et al. 1971, Collos \& Slawyk 1976). These differences probably result from our improvements in the NR assay (Berges \& Harrison 1995a). On the $3 \mathrm{~h}$ time scale measured, NR activity was an adequate predictor of nitrate incorporation rates in the present study.

\section{Effects of nitrate depletion}

Increase in $\mathrm{C}: \mathrm{N}$ ratio has been used as an indicator of nitrogen starvation (e.g. Dortch et al. 1984). In the present study, the increase in this ratio appeared to be driven by increases in cell carbon content and decreases in nitrogen content, indicating that cells were still actively photosynthesizing even though they could incorporate no more nitrogen (see Syrett 1981).

NR activity was again poorly correlated with changes in cell size or biomass, falling rapidly as stationary phase was approached. This decline was comparable to declines in the rates of nitrate incorporation and nutrient depletion. Three patterns of NR activity in response to nitrogen starvation have been noted in the literature. In some cases, NR activity increases after nutrient exhaustion. This has been found in Chlorella spp. (Kessler \& Osterheld 1970), Chlamydomonas reinhardtii (Watt et al. 1992), and in a survey of 6 species of marine phytoplankton (Hipkin et al. 1983); this increase even occurred in cultures that had previously been grown on ammonium and had shown no previous NR activity. It is unclear why this should occur, but suggestions range from a simple derepression of NR synthesis once ammonium is removed, to the presence of oxidative pathways within the cell that provide nitrate in the absence of a nitrogen supply (Watt et al. 1992). It is worth noting, however, that Oaks et al. (1990) showed that trace nitrate contamination of soil was responsible for a 'no nitrate' induction of NR in higher plants. This is clearly a problem in artificial seawater media as well; in the present study up to $1 \mu \mathrm{M}$ nitrate was introduced from trace contamination of reagent grade salts, particularly sodium chloride. A second pattern observed is a constant decline in NR activity after nitrogen depletion (Morris \& Syrett 1965, Eppley et al. 1969). The decrease in NR activity is thought to be the result of enzyme degradation (Syrett 1981), and Hersey \& Swift (1976) hypothesized that NR might be less stable in the absence of nitrate and so be susceptible to degradation. NR activity in cultures depleting nitrate has usually not been well correlated with decreases in nitrate incorporation rates, and even where the correlation has been good, the relationship has not been quantitative; in the case of Morris \& Syrett (1965), NR activity was only sufficient to account for 10 to $12 \%$ of the actual incorporation. In the present study, declines in incorporation and NR activity closely match. These apparently different reponses may also be due to the different time scales over which NR activity has been measured.

\section{Effects of ammonium and ammonium pulsing}

Ammonium-grown cells had larger cell volumes and carbon contents. Since ammonium-grown cultures also 
grew more quickly, these increases in cell volume and carbon may be a reflection of increased growth rate, as previously observed (Thompson et al. 1991, Berges \& Harrison 1993), however, nitrogen content did not differ between ammonium- and nitrate-grown cultures.

NR activities were very close to nitrate utilization rates and calculated rates of incorporation in both nitrate and ammonium pulsed cultures. It is possible that the ammonium pulses were too low to have any effect, since there appears to be a threshold for inhibition effects (Syrett 1981, Dortch 1990). At the growth rates observed, all the ammonium would have been taken up within 2 to $3 \mathrm{~h}$ after the addition. In one ammonium culture $\left(\mathrm{NH}_{4}-1\right)$, where ammonium did not becorne depleted, no NR activity was observed. This was also seen in the field, where ammonium enrichment decreased NR activity to zero. However, activity returned when ammonium levels declined to $2 \mu \mathrm{M}$, a level generally considered to be inhibitory to NR activity and to nitrate uptake (Syrett 1981). As Dortch (1990) points out, such generalizations may not hold in field assemblages. Evidence of ammonium inhibition of NR in natural communities is mostly limited to observational, rather than experimental, data. For example, Packard \& Blasco (1974) present data showing that a decline in NR activity correlated with a decline in nitrate uptake with increasing ammonium concentrations above $0.2 \mu \mathrm{M}$ in samples from coastal Greece. However such correlations cannot prove a causal relationship. Furthermore, true ammonium inhibition of nitrate uptake (i.e. an indirect interaction in which decreases in nitrate uptake vary with ammonium concentration) cannot be distinguished from a simple preference for ammonium (i.e. a direct interaction in which decreases in nitrate uptake are independent of ammonium concentration) under these conditions (Dortch 1990).

How the inhibitions of nitrate uptake and NR activity are mediated remains unclear, but it is generally thought that they are mediated by a product of ammonium assimilation (e.g. glutamine) (Syrett 1981, Flynn 1991). On the other hand, Zehr et al. (1989), using a very sensitive technique involving the radioisotope ${ }^{13} \mathrm{~N}$, reported that cultures of Thalassiosira pseudonana and Dunaliella tertiolecta grown on ammonium were still able to take up and reduce nitrate. This suggests that these species possess a constitutive (i.e. nonammonium-repressible) form of NR. In the replicate ammonium-grown culture $\left(\mathrm{NH}_{4}-2\right)$, ammonium was exhausted and significant NR activity was found. Larsson et al. (1985) found similar results in Scenedesmus obtusiusculus: after ammonium exhaustion NR activity rapidly appeared. In this case, there was also excess nitrate in the medium. Alternatively, Morris \& Syrett (1965) found that in Chlorella vulgaris, an increase in
NR activity followed ammonium exhaustion even when there was no nitrate present. Solomonson \& Barber (1990) concluded, based on several species, that nitrate may not be necessary to induce synthesis of NR. but that removal of ammonium repression is sufficient.

It appears that the inhibition of nitrate incorporation by ammonium (whether at the level of uptake or reduction) is reflected in a decrease in NR activity, although inhibition of nitrate uptake can occur more rapidly than inhibition of NR activity. Changes in NR activity are likely mediated by changes in enzyme protein at longer time scales, but perhaps by an inactivation mechanism at scales of minutes (e.g. Huber et al. 1992). Although such short-term enzyme inactivation might not be well represented in assays of maximal NR activity, because most measurements in the field are concerned with average incorporation over longer periods of time, measurement of maximal NR activity may actually provide a more representative and robust measurement than would assays that attempt to account for the activation state of the enzyme.

In summary, from laboratory work, despite temporal changes in nitrate incorporation rates caused by periodicity in irradiance and nitrate depletion, NR activity closely followed changes in nitrate incorporation, at least on a scale of hours to days. This suggests that NR activity could be useful in natural environments with similar scales of variability. Although ammonium does inhibit NR activity, the inhibition appears to be in step with changes in nitrate uptake. Pulses of ammonium do not appear to influence the relationship either. Based on the results of these experiments, it appears that in the majority of cases, NR activities can adequately predict rates of nitrate incorporation. Our field experiments have successfully applied the modified NR assay to natural assemblages of phytoplankton, and supported the results observed using unialgal cultures. Patterns in diel periodicity of NR activity in laboratory cultures and natural populations were very similar; better resolution will result from more intensive time series. Ammonium 'inhibition' of NR activity in natural populations was apparently less complete and occurred over a much longer time scale than is generally appreciated.

In our experience, NR activity measurements were rapidly and easily performed ship-board; typically, sample collection, filtration and homogenization could be accomplished within $30 \mathrm{~min}$, and data were available within $2 \mathrm{~h}$. Alternatively, preliminary results indicate that NR activity is stable for at least several days when filtered samples are kept frozen in liquid nitrogen (Berges \& Harrison 1995a), opening the possiblity of sample storage for later analyses. Such rapid sample processing is a substantial improvement over ${ }^{15} \mathrm{~N}$ tech- 
niques, where sample processing can often take weeks or longer. ${ }^{15} \mathrm{~N}$ techniques offer the advantage of being able to average results by varying incubation times, but the average is always a function of the processes going on inside the incubation bottles, which are themselves poorly understood (e.g. Collos et al. 1993). NR activity on the other hand provides an instantaneous measurement of the conditions the organism has experienced over a period of time determined by the rate of acclimation of enzyme levels. Such integration is more relevant than variability in chemical measurements, because it is a reflection of variation that is truly meaningful to the organism. As well, because ${ }^{15} \mathrm{~N}$ techniques can be applied to other nitrogen forms including ammonium and dissolved organic nitrogen (e.g. Bronk \& Glibert 1993), NR measurements will not replace them, but rather supplement them. In a future paper we report in detail the relationship between NR activity and nitrate and ammonium utilization in field assemblages of phytoplankton (Cochlan \& Berges unpubl.).

Acknowledgements. The authors acknowledge the valuable advice and comments provided by Drs A. D. M. Glass, R. W. Brownsey, T T Packard, and 2 anonymous reviewers. We thank Maureen Soon for her assistance with CNS analyses, Dr K. Yin for help with AutoAnalyzer methods, and Anne Fisher for support during diel laboratory experiments. We thank the Captain and crew of the RV 'Point Sur', and Dr R. C. Dugdale for inviting us to participate in the Shift-Up cruise. Research was supported through NSERC operating grants to P.J.H., and an NSERC and Killam fellowships to J.A.B. W.P.C. was supported by the NOAA National Sea Grant College Program under grant no. NA90AA-D-SG-525, and the California State Resources Agency.

\section{LITERATURE CITED}

Antia NJ, Harrison PJ, Oliveira L (1991) The role of dissolved organic nitrogen in phytoplankton nutrition, cell biology and ecology. Phycologia 30:1-89

Berges JA, Harrison PJ (1993) Relationship between nucleoside diphosphate kinase activity and light-limited growth rate in the marine diatom Thalassiosira pseudonana (Bacillariophyceae). J Phycol 29:45-53

Berges JA, Harrison PJ (1995a) Nitrate reductase activity quantitatively predicts the rate of nitrate incorporation under steady-state light limitation: a revised assay and characterization of the enzyme in three species of marine phytoplankton. Limnol Oceanogr 40(1):82-93

Berges JA, Harrison PJ (1995b) Relationships between nitrate reductase activity and rates of growth and nitrate incorporation under steady-state light or nitrate limitation in the marine diatom Thalassiosira pseudonana (Bacillariophyceae). J Phycol 31:85-95

Berges JA, Virtanen C (1993) Expanding the capablities of laboratory instruments using built-in microprocessors and serial interfaces: adapting an LKB Ultrospec II UV spectrophotometer for scanning and enzyme kinetic analyses. Comput Biol Med 23:131-141
Blasco D, Maclsaac JJ, Packard TT, Dugdale RC (1984) Relationship between nitrate reductase and nitrate uptake in phytoplankton in the Peru upwelling region. Limnol Oceanogr 29:275-286

Bronk DA, Glibert PM (1993) Application of a ${ }^{15} \mathrm{~N}$ tracer method to the study of dissolved organic nitrogen uptake during spring and summer in Chesapeake Bay. Mar Biol 115:501-508

Campbell WH (1988) Nitrate reductase and its role in nitrate assimilation in plants. Physiol Plant 74:214-219

Chisholm SW (1981) Temporal patterns of cell division in unicellular algae. Can Bull Fish Aquat Sci 210:150-181

Cochlan WP, Harrison PJ, Denman KL (1991) Diel periodicity of nitrogen uptake by marine phytoplankton in nitraterich environments. Limnol Oceanogr 36:1689-1700

Collos Y, Descolas-Gros C, Fontugne M, Mortain-Bertrand A, Cretiennot-Dinet MJ, Frikha MG (1993) Chemical, isotopic and enzymatic monitoring of free and enclosed seawater: implications for primary production estimates in incubation bottles. Mar Ecol Prog Ser 93:49-54

Collos Y, Slawyk G (1976) Significance of cellular nitrate content in natural populations of marine phytoplankton growing in shipboard cultures. Mar Biol 34:27-32

Collos Y, Slawyk G (1977) Nitrate reductase as a function of in situ nitrate uptake and environmental factors of euphotic zone profiles. J exp mar Biol Ecol 29:119-130

Collos Y, Slawyk G (1980) Nitrogen uptake and assimilation by marine phytoplankton. In: Falkowski PG (ed) Primary productivity in the sea. Plenum Press, New York, p 195-211

Deng MD, Moureaux $T$, Cherel I, Boutin JP, Caboche $M$ (1991) Effects of nitrocen metabolites on the regulation and circadian expression of tobacco nitrate reductase. Plant Physiol \& Biochem 29:239-247

Dortch Q (1990) The interaction between ammonium and nitrate uptake in phytoplankton. Mar Ecol Prog Ser 61: $183-201$

Dortch Q. Ahmed SI, Packard TT (1979) Nitrate reductase and glutamate dehydrogenase activities in Skeletonema costatum as measures of nitrogen assimilation rates. J Plankton Res 1:169-185

Dortch Q, Clayton JR Jr, Thoressen SS, Ahmed SI (1984) Species differences in accumulation of nitrogen pools in phytoplankton. Mar Biol 81:237-250

Eppley RW (1978) Nitrate reductase in marine phytoplankton In: Hellebust JA, Craige JS (eds) Handbook of phycological methods. Physiological and biochemical methods. Cambridge University Press, Cambridge, p 217-223

Eppley RW (1981) Relations between nutrient assimilation and growth rate in phytoplankton with a brief review of estimates of growth rate in the ocean. Can Bull Fish Aquat Sci 210:251-263

Eppley RW, Coatsworth JL, Solorzano L (1969) Studies of nitrate reductase in marine phytoplankton. Limnol Oceanogr 14:194-205

Eppley RW, Rogers JN, MCCarthy JJ, Sournia A (1971) Light/ dark periodicity in nitrogen assimilation of the marine phytoplankters Skeletonema costatum and Coccolithus huxleyi in N-limited chemostat culture. J Phycol 7:150-154

Flynn KJ (1991) Algal carbon-nitrogen metabolism: a biochemical basis for modelling the interactions between nitrate and ammonium uptake. J Plankton Res 13:373-387

Flynn KJ, Zapata M, Garrido JL, Opik H, Hipkin CR (1993) Changes in carbon and nitrogen physiology during ammonium and nitrate nutrition and nitrogen starvation in Isochrysis galbana. Eur J Phycol 28:47-52

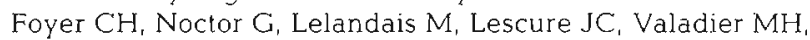
Boutin JP, Horton P (1994) Short-term effects of nitrate, 
nitrite and ammonium assinilation on photosynthesis, carbon partitioning and protein phosphorylation in maize. Planta 192:211-220

Friederich GE, Whitledge TE (1972) Autoanalyzer procedures for nutrients. In: Pavlov SP (ed) Phytoplankton growth dynamics, Technical series 1, Chemostat methodology and chemical analyses. Spec Rep Dept Oceanogr Univ Wash 52:38-55

Gao Y, Smith GJ, Alberte RS (1992) Light regulation of nitrate reductase in Ulva fenestrata (Chlorphyceae). Mar Biol 112:691-696

Glibert PM, Garside C (1992) Diel variability in nitrogenous nutrient uptake by phytoplankton in the Chesapeake Bay plume. J Plankton Res 14:271-288

Harrison PJ, Waters RE, Taylor FJR (1980) A broad spectrum artificial seawater medium for coastal and open ocean phytoplankton. J Phycol 16:28-35

Harrison WG (1976) Nitrate metabolism of the red tide dinoflagellate Gonyaulax polyedra Stein. J exp mar Biol Ecol 21:199-209

Hersey RL, Swift E (1976) Nitrate reductase activity of Amphidinium carteri and Cachonina nei (Dinophyceae) in batch culture: diel periodicity and effects of light intensity and ammonia. J Phycol 12:36-44

Hipkin CR, Thomas RJ, Syrett PJ (1983) Effects of nitrogen deficiency on nitrate reductase, nitrate assimilation and photosynthesis in unicellular marine algae. Mar Biol 77 : $101-105$

Huber JL, Huber SC, Campbell WH, Redinbaugh MG (1992) Reversible light/dark modulation of spinach leaf nitrate reductase activity involves protein phosphorylation. Arch Biochem Biophys 296:58-65

Kessler E, Osterheld $H(1970)$ Nitrification and induction of nitrate reductase in nitrogen-deficient algae. Nature 228 : $287-288$

Larsson et al. (1985) Photosynthetic nitrogen metabolism in high and low $\mathrm{CO}_{2}$-adapted Scenedesmus. J exp Bot 36: $1387-1395$

Leftley JW, Bonin DJ, Maestrini SY (1983) Problems in estimating marine phytoplankton growth, productivity and metabolic activity in nature: an overview of methodology Oceanogr mar Biol A Rev 21:23-66

Lillo C (1983) Studies of diurnal variations of nitrate reductase activity in barley leaves using various assay methods. Physiol Plant 57:357-362

Martinez R, Packard TT, Blasco D (1987) Light effects and diel variations of nitrate reductase activity in phytoplankton from the northwest Africa upwelling region. Deep Sea Res $34: 741-753$

Morris I, Syrett PJ (1965) The effect of nitrogen starvation on the activity of nitrate reductase and other enzymes in Chlorella. J gen Microbiol 38:21-28

Nelson DM, Brand LE (1979) Cell division periodicity in 13 species of marine phytoplankton on a light:dark cycle. J Phycol 15:67-75

Oaks A, Long DM, Zoumadakis M, Li XZ, Hertig C (1990) The role of $\mathrm{NO}_{3}^{-}$and $\mathrm{NH}_{4}^{+}$ions in the regulation of nitrate

This article was submitted to the editor reductase in higher plants. In: Ullrich WR, Rigano C, Fuggi A, Aparicio PJ (eds) Inorganic nitrogen in plants and microorganisms. Springer-Verlag, Berlin, p 165-170

Packard TT, Blasco D (1974) Nitrate reductase activity in upwelling regions. 2. Ammonia and light dependence Téthys 6:269-280

Packard TT, Blasco D, Maclsaac JJ, Dugdale RC (1971) Variations of nitrate reductase activity in marine phytoplankton. Invest pesq 35:209-219

Parsons TR, Maita Y, Lalli CM (1984) A manual of chemical and biological methods for seawater analysis. Pergamon Press, New York

Prezelin BB (1992) Diel periodicity in phytoplankton productivity. Hydrobiologia 238:1-35

Ramalho CB, Hastings JW, Colepicolo P (1995) Circadian oscillation in nitrate reductase activity in Gonyaulax polyedra is due to changes in cellular protein levels. Plant Physiol 107:225-231

Scholl RL, Harper JE, Hageman RH (1974) Improvements of the nitrite color development in assays of nitrate reductase by phenazine methosulfate and zinc acetate. Plant Physiol $53: 825-828$

Serra JL, Llama MJ, Cadenas E (1978) Nitrate utilization by the diatom Skeletonema costatum. Plant Physiol 62 991-994

Slawyk G, Rodier M (1986) Glutamine synthetase activity in Chaetoceros affinis (Bacillariophyceae): comparison with other estimates of nitrogen utilization during nutrient perturbation. J Phycol 22:270-275

Smith GJ, Zimmerman RC, Alberte RS (1992) Molecular and physiological responses of diatoms to variable levels of irradiance and nitrogen availability: growth of Skeletonema costatum in simulated upwelling conditions. Limnol Oceanogr 37:989-1007

Solomonson LP, Barber MJ (1990) Assimilatory nitrate reductase: functional properties and regulation. A Rev Plant Physiol Plant Mol Biol 41:225-253

Syrett PJ (1981) Nitrogen metabolism of microalgae. Can Bull Fish Aquat Sci 210:182-210

Syrett PJ, Peplinska AM (1988) Effects of nitrogen-deprivation and recovery from it, on the metabolism of microalgae New Phytol 109:289-296

Thompson PA, Harrison PJ, Parslow JS (1991) Influence of irradiance on cell volume and carbon quota in ten species of marine phytoplankton. J Phycol 27:351-360

Watt DA, Amory AM, Cresswell CF (1992) Effect of nitrogen supply on the kinetics and regulation of nitrate assimilation in Chlamydomonas reinhardtii Dangeard. J exp Bot 43:605-615

Wheeler PA (1983) Phytoplankton nitrogen metabolism. In: Carpenter EJ, Capone DG (eds) Nitrogen in the marine environment. Academic Press, New York, p 309-346

Wilkinson L (1990) SYSTAT: the system for statistics. SYSTAT Inc., Evanston

Zehr JP, Capone DG, Falkowski PG (1989) Rapid incorporation of ${ }^{13} \mathrm{NO}_{3}$ by $\mathrm{NH}_{4}$-limited phytoplankton. Mar Ecol Prog Ser 51:237-241

Manuscript first received: November 4, 1994

Revised version accepted: March 23, 1995 